\title{
Antibodies reactive with Bartonella henselae and Ehrlichia canis in dogs from the communal lands of Zimbabwe
}

\author{
P J Kelly ${ }^{\mathrm{a}^{*}}, \mathrm{G}$ Nic Eoghain ${ }^{\mathrm{b}^{\dagger}}$ and D Raoult ${ }^{\mathrm{c}}$
}

\begin{abstract}
The prevalences of antibodies against Bartonella henselae and Ehrlichia canis were determined in sera from 228 dogs in 5 communal lands of Zimbabwe, areas where traditional subsistence agro-pastoralism is practised. The sera were collected from apparently healthy dogs during routine rabies vaccination programmes and tested with indirect fluorescent antibody assays using B. henselae (Houston-I) and E. canis (Oklahoma) as antigens. We found reactive antibodies $(\geq 1: 80)$ against $B$. henselae in $14 \%$ of the dogs tested. Seropositive animals were found in Bikita (41\%; 17/42), Omay $(13 \% ; 6 / 48)$, Chinamora $(5 \% ; 2 / 38)$ and Matusadona $(15 \% ; 7 / 48)$. No seropositive dogs were found in Chiredzi $(0 \% ; 0 / 52)$. Antibodies reactive with $E$. canis $(\geq 1: 80)$ were found in $34 \%$ of the dogs tested, from Bikita $(88 \% ; 37 / 42)$, Chiredzi (31\%; 16/52), Omay (17 \%; 8/48), Chinamora $(26 \% ; 10 / 38)$ and Matusadona $(15 \% ; 7 / 48)$. Our survey shows dogs in the communal lands of Zimbabwe are frequently exposed to E. canis and B. henselae or closely related species. Further studies are indicated to determine the pathogenicity of the organisms infecting these dogs and their clinical significance.

Key words: Bartonella, communal lands, dogs, Ehrlichia, serosurvey, Zimbabwe.

Kelly P J, Nic Eoghain G, Raoult D Antibodies reactive with Bartonella henselae in dogs from the communal lands of Zimbabwe. Journal of the South African Veterinary Association (2004) 75(3): 116-120 (En.). Institute of Veterinary, Animal and Biomedical Sciences, Massey University, Private Bag 11 222, Palmerston North, New Zealand.
\end{abstract}

\section{INTRODUCTION}

Ehrlichia canis is a Gram-negative bacterium that is an agent of canine monocytic ehrlichiosis ${ }^{29}$. The organism is transmitted by Rhipicephalus sanguineus and, in the acute stage of infection, there is often fever, anorexia, lymphadenomegaly, splenomegaly and thrombocytopaenia. Most dogs survive the acute stage and enter the subclinical phase of the disease, which might last for years. During this phase, animals are apparently healthy although thrombocytopaenia is common. Dogs may spontaneously eliminate $E$. canis during the subclinical phase $\mathrm{e}^{6,21}$ or go on to develop the chronic phase of the disease in which there is marked weight loss and signs resulting from pancytopaenia. While serosurveys have shown that high percentages of urban dogs in Zimbabwe have antibodies reactive with

anstitute of Veterinary, Animal and Biomedical Sciences Massey University, Private Bag 11 222, Palmerston North, New Zealand.

${ }^{\mathrm{b}}$ Faculty of Veterinary Science, University College of Dublin, Dublin, Ireland.

'Unité des Rickettsies, Faculté de Médecine, Université Aix-Marseille, France.

${ }^{*}$ Author for correspondence.

E-mail: p.kelly@massey.ac.nz

${ }^{\dagger}$ Present address: Mountainview Drive, Bray, Co Wicklow, Ireland.

Received: June 2004. Accepted: August 2004.
E. $_{\text {canis }}{ }^{36-38}$, there are no published data on infections in dogs in the rural communal lands. These are areas where traditional subsistence agro-pastoralism is practised and which contain $70 \%$ of the national dog population ${ }^{10}$.

Bartonella henselae is a Gram-negative bacterium that is an emerging human and veterinary pathogen worldwide ${ }^{23}$. The domestic cat is the natural host of $B$. henselae and high percentages of cats have asymptomatic bacteraemia which may persist for years ${ }^{32}$. Seropositive animals have been found in Zimbabwe $(24 \%$; $28 / 119)$ and South Africa $(21 \% ; 11 / 52)^{27}$ and $B$. henselae has been isolated from the blood of domestic cats in Zimbabwe $(10 \% ; 3 / 30)^{28}$ and South Africa $(3 \% ; 1 / 31)^{44}$.

In humans, $B$. henselae is an important emerging zoonotic agent that is often associated with contact with cats and their fleas ${ }^{23}$. The organism has been implicated as an agent of an ever-increasing spectrum of diseases including cat-scratch disease, bacillary angiomatosis, endocarditis, bacteraemia, encephalopathy, neuroretinitis, osteomyelitis and peliosis hepatis $^{27}$. Immunosuppressed people are often at particular risk of infection with $B$. henselae and a recent study in South Africa found $10 \%$ of outpatients attend- ing HIV clinics in Johannesburg had Bartonella bacteraemia ${ }^{19}$.

Bartonella henselae is transmitted between cats by the cat flea, Ctenocephalides felis ${ }^{14}$, which has a broad host range and is also commonly found on $\mathrm{dogs}^{49}$. Recent studies have shown that $B$. henselae can infect dogs and cause clinical disease ${ }^{20,31,39}$. Ctenocephalides felis is a common ectoparasite of dogs in southern Africa ${ }^{12}$, particularly in dogs in the communal lands of Zimbabwe where ectoparasite control is seldom used.

To determine if antibodies to $B$. henselae were present in dogs in Zimbabwe, a serosurvey on dogs from 5 widely separated communal lands was conducted. The dogs were also tested for antibodies to $E$. canis to provide data on the prevalence of canine ehrlichiosis in the rural areas of Zimbabwe. The results of our surveys are described in this report.

\section{MATERIALS AND METHODS}

\section{Sera}

Blood samples were obtained from apparently healthy dogs ( $\geq 20$ weeks of age) during rabies vaccination programmes in communal lands in central (Chinamora, -17.58, 31.25), southeast (Chiredzi, -21.00, 31.50; Bikita, -20.07, 31.60) and northern (Matusadona, -16.43 , 28.58; Omay, -17.08, 28.25) Zimbabwe. Sera were separated and stored at $-20^{\circ} \mathrm{C}$ until indirect fluorescent antibody assays (IFA) were performed. Negative and positive control sera for the IFAs were identified from studies performed previously in our laboratories ${ }^{27,37}$.

\section{Indirect fluorescent antibody assays}

Bartonella henselae (Houston-I; ATCC 49882) was grown in Vero cells as described previously ${ }^{27}$. When $60-90 \%$ of the cells were infected they were pelleted, washed and resuspended in phosphate buffered saline, applied ( $5 \mu l$ aliquots) to the wells of 32 well Teflon slides and air-dried. E. canis (Oklahoma) was grown in DH82 continuous cell cultures, harvested and applied to the wells of Teflon-coated slides as described previously $^{38}$. 
Table 1: Ages of dogs sampled in 5 communal lands in Zimbabwe.

\begin{tabular}{|c|c|c|c|c|c|c|}
\hline & $n$ & $\leq 1$ year & $>1$ to $\leq 2$ years & $>2$ to $\leq 3$ years & $>3$ to $\leq 4$ years & $>4$ years \\
\hline Bikita & 42 & 14 (33\%) & 17 (41\%) & $4(10 \%)$ & $5(12 \%)$ & $2(5 \%)$ \\
\hline Chinamora & 38 & $16(42 \%)$ & $5(13 \%)$ & $9(24 \%)$ & $5(13 \%)$ & $3(8 \%)$ \\
\hline Chiredzi & 52 & $15(29 \%)$ & $21(40 \%)$ & $9(17 \%)$ & $3(6 \%)$ & $4(8 \%)$ \\
\hline Omay & 48 & $15(31 \%)$ & $12(28 \%)$ & $14(29 \%)$ & $4(8 \%)$ & $3(6 \%)$ \\
\hline Matusadona & 48 & $14(29 \%)$ & $13(27 \%)$ & $13(27 \%)$ & $5(10 \%)$ & $3(6 \%)$ \\
\hline Total & 228 & 74 (33\%) & $68(30 \%)$ & $49(22 \%)$ & $22(10 \%)$ & $15(7 \%)$ \\
\hline
\end{tabular}

$n=$ sample size

Table 2: Ages and percentages of dogs from communal lands in Zimbabwe with indirect fluorescent antibody titres of $\geq 1: 80$ against Ehrlichia canis.

\begin{tabular}{lllcrrr}
\hline & Overall & $\mathbf{1}$ year & $>$ 1 to $\leq \mathbf{2}$ years & $>$ 2 to $\leq \mathbf{3}$ years & $>\mathbf{3}$ to $\leq \mathbf{4}$ years & $>\mathbf{4}$ years \\
\hline Bikita & $88 \%(37 / 42)$ & $86 \%(12 / 14)$ & $88 \%(15 / 17)$ & $100 \%(4 / 4)$ & $100 \%(5 / 5)$ & $50 \%(1 / 2)$ \\
Chiredzi & $31 \%(16 / 52)$ & $20 \%(3 / 15)$ & $38 \%(8 / 21)$ & $33 \%(3 / 9)$ & $33 \%(1 / 3)$ & $25 \%(1 / 4)$ \\
Omay & $17 \%(8 / 48)$ & $33 \%(5 / 15)$ & $0 \%(0 / 12)$ & $7 \%(1 / 14)$ & $25 \%(1 / 4)$ & $33 \%(1 / 3)$ \\
Chinamora & $26 \%(10 / 38)$ & $38 \%(6 / 16)$ & $40 \%(2 / 5)$ & $11 \%(1 / 9)$ & $20 \%(1 / 5)$ & $0 \%(0 / 3)$ \\
Matusadona & $15 \%(7 / 48)$ & $36 \%(5 / 14)$ & $0 \%(0 / 13)$ & $8 \%(1 / 13)$ & $20 \%(1 / 5)$ & $0 \%(0 / 3)$ \\
Total & $34 \%(78 / 228)$ & $42 \%(31 / 74)$ & $37 \%(25 / 68)$ & $20 \%(10 / 49)$ & $41 \%(9 / 22)$ & $20 \%(3 / 15)$ \\
\hline
\end{tabular}

Reactive antibodies were detected against $B$. henselae and E. canis using previously reported IFA procedures ${ }^{27,37}$ and fluorescein isothiocyanate-labelled protein $\mathrm{G}$ conjugate (Biogenesis Inc, Sandown, NH, USA). Based on the results of previous studies, sera with IFA titres of $\geq 1: 80$ were regarded as positive for previous exposure to Bartonella spp. ${ }^{24,27}$ or to Ehrlichia spp. ${ }^{37,38}$.

\section{RESULTS}

\section{Sera}

Sera were obtained from 228 dogs in the 5 communal lands surveyed. Over half of the dogs sampled $(142 / 228 ; 62 \%)$ were 2 years of age or younger (Table 1 ).

\section{Indirect fluorescent antibody assays}

Dogs with antibodies against E. canis were found in all the communal lands sampled (Table 2) and seroprevalences varied from $15 \%$ (7/48 in Matusadona) to $88 \%$ (37/42 in Bikita). There were no significant differences between the overall seroprevalences in the different age groups of dogs studied. High antibody titres (arbitrarily defined as $\geq 1: 640$ ) were only found in dogs 3 years of age or younger from Chinamora $(5 ; 50 \%$ of the positive dogs), Chiredzi $(11 ; 69 \%$ of positive dogs) and Bikita (23; $63 \%$ of the positive dogs).

Dogs with antibodies against $B$. henselae were found in all communal lands apart from Chiredzi (Table 3). There was no obvious correlation between age and seropositivity. The highest seroprevalence was in dogs from Bikita $(41 \%)$ where the only high titres against $B$. henselae, arbitrarily defined as $\geq 1: 640$, were found in 4 dogs which were 2 years of age or younger.

\section{DISCUSSION}

In 1990, Brooks ${ }^{10}$ reported that dogs under a year of age constituted $33 \%$ of the population in Manicaland Province in the east of Zimbabwe and that only $11 \%$ of dogs were over 4 years of age. A similar age distribution was reported subsequently in $2000^{13}$ and has now also been found in this study (Table 1). It appears that there has been little improvement in the very rapid turnover of dogs in the communal lands of Zimbabwe in the past decade.

This study is the 1st to show that rural dogs in southern Africa have high prevalences of antibodies to E. canis. The percentage of communal land dogs we found seropositive against E. canis (34\%) is similar to that described previously for urban dogs in Zimbabwe and South Africa $(33-42 \%)^{36-38,43}$. Although local experience indicates infections with $E$. canis are frequent in southern Africa ${ }^{29,53}$, there is little direct supporting evidence. There are no African isolates of $E$. canis and only 3 reports identifying E. canis or a closely related species on the continent. In a recent report, only a few positive results were obtained when dogs suspected of having canine ehrlichiosis in South Africa were tested for $E$. canis with a highly sensitive and specific PCR assay ${ }^{2}$. In a study using PCR and sequencing, organisms closely related to E. canis have been identified in a sheep in South Africa ${ }^{1}$. Using similar methods, organisms closely related to E. canis have been identified in cattle ticks from Mali and Niger, but DNA of Ehrlichia spp. was not found in 86 $R$. sanguineus from dogs in Mali and Sudan $^{42}$.

Although antibodies to E. canis were detected, there is serological crossreactivity between members of the genus and we could not, then, determine the

Table 3: Ages and percentages of dogs from communal lands in Zimbabwe with indirect fluorescent antibody titres of $\geq 1: 80$ against Bartonella henselae.

\begin{tabular}{lcccrrr}
\hline & Overall & 1 year & $>$ 1 to $\leq \mathbf{2}$ years & $>$ 2 to $\leq \mathbf{3}$ years & $>$ 3 to $\leq \mathbf{4}$ years & $>\mathbf{4}$ years \\
\hline Bikita & $41 \%(17 / 42)$ & $7 \%(1 / 14)$ & $53 \%(9 / 17)$ & $100 \%(4 / 4)$ & $40 \%(2 / 5)$ & $50 \%(1 / 2)$ \\
Chiredzi & $0 \%(0 / 52)$ & $0 \%(0 / 30)$ & $0 \%(0 / 21)$ & $0 \%(0 / 9)$ & $0 \%(0 / 3)$ & $0 \%(0 / 4)$ \\
Omay & $13 \%(6 / 48)$ & $20 \%(3 / 15)$ & $0 \%(0 / 12)$ & $7 \%(1 / 14)$ & $0 \%(0 / 4)$ & $66 \%(2 / 3)$ \\
Chinamora & $5 \%(2 / 38)$ & $13 \%(2 / 16)$ & $0 \%(0 / 5)$ & $0 \%(0 / 9)$ & $0 \%(0 / 5)$ & $0 \%(0 / 3)$ \\
Matusadona & $15 \%(7 / 48)$ & $29 \%(4 / 14)$ & $0 \%(0 / 13)$ & $8 \%(1 / 13)$ & $0 \%(0 / 5)$ & $66 \%(2 / 3)$ \\
Total & $14 \%(32 / 228)$ & $14 \%(10 / 74)$ & $13 \%(9 / 68)$ & $12 \%(6 / 49)$ & $9 \%(2 / 22)$ & $33 \%(5 / 15)$ \\
\hline
\end{tabular}


Ehrlichia spp. that had infected the dogs we studied. There is extensive serological cross-reactivity between $E$. canis and $E$. chaffeensis ${ }^{47}$, the agent of human monocytic ehrlichiosis. The organism can also infect dogs and cause clinical and pathological signs indistinguishable from those caused by E. canis ${ }^{7}$. Although antibodies to E. chaffeensis have been found in both $\operatorname{dogs}^{43}$ and people in southern Africa $^{11,45}$, all available information indicates that E. chaffeensis only occurs in the USA and it is thus unlikely that infections with the organism influenced our results.

Ehrlichia ruminantium (formerly Cowdria ruminantium) is the agent of heartwater, a disease of domestic ruminants that occurs widely in Africa and is transmitted by Amblyomma spp. Experimentally infected dogs do not show clinical signs or laboratory abnormalities but become bacteraemic for up to 3 weeks and seroconvert against E. ruminantium ${ }^{26}$. There is extensive antigenic cross-reactivity between $E$. canis and E. ruminantium with dogs experimentally infected with E. ruminantium becoming positive in IFA and immunoblots against E. canis $^{26,38}$. Recently, PCR and sequencing studies identified the DNA of an E. ruminantium in dogs in South Africa ${ }^{2}$ and Amblyomma spp. have been found on dogs in the region ${ }^{12}$. Although we did not determine the ticks on the dogs in our study, Amblyomma spp. occur widely in Zimbabwe ${ }^{51}$ and it would appear likely that at least some of the seropositive dogs had been infected with an E. ruminantium or a closely related organism.

Other recognised Ehrlichia spp. that are closely related to $E$. canis and have serological cross-reactivity are E. muris which infects mice, and perhaps people, in $\operatorname{Japan}^{25}$ and E. ewingii which is an agent of canine granulocytic ehrlichiosis that has only been reported in the USA ${ }^{33}$. Although it is very unlikely that these organisms influenced our results, there are other incompletely characterised Ehrlichia and Anaplasma spp. that have been described in southern Africa ${ }^{1,2,51}$ and their role as pathogens in dogs is yet to be determined. With the apparent high exposure of dogs in southern Africa to Ehrlichia spp. and/or closely related organisms, further studies are indicated to determine the organisms involved and their role in the rapid turnover of dogs in the region.

Bartonella henselae is known to infect both cats $^{27,28,44}$ and people ${ }^{19}$ in southern Africa and our study now provides evidence that infections also occur in dogs. We found a significant prevalence (14\%) of antibodies against B. henselae in dogs from widely separated communal lands in Zimbabwe. Similar seropre- valences have been found in dogs from the United Kingdom $(6.5 \%)^{3}$, Hawaii $(3 \%)^{18}$ and Japan $(8 \%)^{52}$. These findings are consistent with the reported widespread distribution of $B$. hensela $e^{27}$ and its vector, the cat flea ${ }^{49}$.

There are only limited data on the effects of $B$. henselae in dogs. Experimental infections cause no detectable clinical signs or result in short-lived bacteraemia ${ }^{31}$. Natural infections have been associated with peliosis hepatis ${ }^{31}$, a vasculoproliferative disorder characterised by cystic, blood-filled spaces in the liver, and pyogranulomatous hepatitis ${ }^{20}$. Bartonella henselae has also been found in 3 dogs suffering from various conditions with a wide variety of historical, clinical, haematological, and biochemical abnormalities $^{39}$.

While there is no serological crossreactivity between Bartonella spp. and E. canis and spotted fever group rickettsiae ${ }^{9}$, serological cross-reactivity has been reported between $B$. henselae and other members of the genus. There is extensive cross-reactivity with $B$. quintana $a^{22}$ which causes trench fever, bacillary angiomatosis and endocarditis in people and is transmitted by the human body louse (Pediculus humanus). Although B. quintana occurs in people in Africa $^{46}$, there are no reports of infections occurring in dogs and it would appear unlikely, then, that the organism was responsible for the antibodies we detected.

Serological cross-reactivity has also been described between $B$. henselae and $B$. clarridgeiae $^{50}$. The cat flea is the presumed vector of $B$. clarridgeiae ${ }^{48}$ and the natural reservoir is the cat, in which the organism causes a chronic asymptomatic bacteraemia ${ }^{34}$. Bartonella clarridgeiae also infects dogs and has been associated with vegetative endocarditis ${ }^{15}$ and Doberman hepatopathy ${ }^{20}$. Although there are no reports of $B$. clarridgeiae in Africa, the organism occurs very widely ${ }^{30}$ in North and South America, Europe, South East Asia and New Zealand. It would appear likely, then, that B. clarridgeiae occurs in Africa and that infections with the organism occurred in at least some of the dogs that were studied.

Other Bartonella spp. are known pathogens of dogs but appear unlikely to have influenced our results. Bartonella vinsonii subspecies berkhoffii was the 1st Bartonella spp. to be identified as a pathogen in $\mathrm{dogs}^{5}$ and has been reported in dogs with arrhythmias and endocarditis ${ }^{8}$, granulomatous lymphadenitis, granulomatous rhinitis ${ }^{41}$ and anterior uveitis and choroiditis $^{40}$. Although an IFA study using B. vinsonii subspecies berkhoffii as antigen found $65 \%$ of dogs from the Sudan to be seropositive $^{17}$, antibodies to B. vinsonii subspecies berkhoffii do not react with $B$. henselae and would not thus have been detected in our study. Further experiments using specific serological and/or molecular tests for $B$. vinsonii subspecies berkhoffii are required to determine if the organism occurs in southern Africa. Bartonella elizabethae has been identified in a dog with a wide variety of clinical and laboratory abnormalities ${ }^{39}$ but the organism has only been found in the Americas ${ }^{4}$ and there appears to be only minor serological cross-reactivity between $B$. henselae and B. elizabetha $\mathrm{e}^{35}$. Bartonella washoensis has been found in a dog with mitral valve endocarditis ${ }^{16}$ and, although serological cross-reactivity with $B$. henselae has not been determined, it would appear unlikely that we detected antibodies against $B$. washoensis as the organism has only been described in the United States.

In summary, our study has shown that dogs in widely separated rural areas of Zimbabwe, and hence probably the region, are not uncommonly infected with E. canis and B. henselae or closely related species. Veterinarians should be aware that these organisms might cause disease in their canine patients and laboratories should offer appropriate diagnostic tests. Further studies are indicated to determine the Ehrlichia spp. and Bartonella spp. that occur in southern Africa and the role they play as pathogenic agents.

\section{ACKNOWLEDGEMENTS}

Funding was provided by the European Union-funded link between the Veterinary Faculties of the University of Zimbabwe and University of Utrecht. We thank Anne-Marie Pretorius for providing the protein $\mathrm{G}$ conjugate.

\section{REFERENCES}

1. Allsopp M, Visser E S, du Plessis J L, Vogel S W, Allsopp B A 1997 Different organisms associated with heartwater as shown by analysis of $16 \mathrm{~S}$ ribosomal RNA gene sequences. Veterinary Parasitology 71: 283300

2. Allsopp M T, Allsopp B A 2001 Novel Ehrlichia genotype detected in dogs in South Africa. Journal of Clinical Microbiology 39: 4204-4207

3. Barnes A, Bell S C, Isherwood D R, Bennett M, Carter S D 2000 Evidence of Bartonella henselae infection in cats and dogs in the United Kingdom. Veterinary Record 147: 673-677

4. Birtles R J, Canales J, Ventosilla P, Alvarez E, Guerra H, Llanos-Cuentas A, Raoult D, Doshi N, Harrison T G 1999 Survey of Bartonella species infecting intradomicillary animals in the Huayllacallan Valley, Ancash, Peru, a region endemic for human bartonellosis. American Journal of Tropical Medicine and Hygiene 60: 799-805

5. Breitschwerdt E B, Kordick D L, Malarkey D 
E, Keene B, Hadfield T L, Wilson K 1995 Endocarditis in a dog due to infection with a novel Bartonella subspecies. Journal of Clinical Microbiology 33: 154-160

6. Breitschwerdt E B, Hegarty B C, Hancock S I 1998 Doxycycline hyclate treatment of experimental canine ehrlichiosis followed by challenge inoculation with two Ehrlichia canis strains. Antimicrobial Agents and Chemotherapeutics 42: 362-368

7. Breitschwerdt E B, Hegarty B C, Hancock S I 1998 Sequential evaluation of dogs naturally infected with Ehrlichia canis, Ehrlichia chaffeensis, Ehrlichia equi, Ehrlichia ewingii, or Bartonella vinsonii. Journal of Clinical Microbiology 36: 2645-2651

8. Breitschwerdt E B, Atkins C E, Brown T T, Kordick D L, Snyder P S 1999 Bartonella vinsonii subsp. berkhoffii and related members of the alpha subdivision of the Proteobacteria in dogs with cardiac arrhythmias, endocarditis, or myocarditis Journal of Clinical Microbiolooy 37: 3618-3626

9. Breitschwerdt E B, Suksawat J, Chomel B, Hegarty B C 2003 The immunologic response of dogs to Bartonella vinsonii subspecies berkhoffii antigens: as assessed by Western immunoblot analysis. Journal of Veterinary Diagnostic Investigation 15 349-354

10. Brooks R 1990 Survey of the dog population of Zimbabwe and its level of rabies vaccination. Veterinary Record 127: 592-596

11. Brouqui P, Le Cam C, Kelly P J, Laurens R, Tounkara A, Sawadogo S, Velo M, Gondao L, Faugere B, Delmont J, et al. 1994 Serologic evidence for human ehrlichiosis in Africa. European Journal of Epidemiology 10: 695-698

12. Bryson N R, Horak I G, Höhn E W, Louw J P 2000 Ectoparasites of dogs belonging to people in resource-poor communities in North West Province, South Africa Journal of the South African Veterinary Association 71: 175-179

13. Butler J R, Bingham J 2000 Demography and dog-human relationships of the dog population in Zimbabwean communa lands. Veterinary Record 147: 442-446

14. Chomel B B, Kasten R W, Floyd-Hawkins K Chi B, Yamamoto K, Roberts-Wilson J Gurfield A N, Abbott R C, Pedersen N C, Koehler J E 1996 Experimental transmission of Bartonella henselae by the cat flea. Journal of Clinical Microbiology 34: 1952-1956

15. Chomel B B, MacDonald K A, Kasten R W Chang C C, Wey A C, Foley J E, Thomas W P Kittleson M D 2001 Aortic valve endocarditis in a dog due to Bartonella clarridgeiae. Journal of Clinical Microbiology 39: 3548-3554

16. Chomel B B, Wey A C, Kasten R W 2003 Isolation of Bartonella washoensis from a dog with mitral valve endocarditis. Journal of Clinical Microbiology 41: 5327-5332

17. Davoust B, Drancourt M, Boni M, Parzy D Seignot J, Roux V 1999 Survey of seroprevalence of Bartonella vinsonii, Ehrlichia canis, and Coxiella burnetii in dogs in southeast France, French Guyana, Martinique, Senegal, Ivory Coast and Sudan [abstract]. In: Proceedings of the European Working Group on Rickettsia, Coxiella, Ehrlichia and Bartonella, Marseilles, France 1999: 90. EUWOG and American Society for Rickettsiology Joint Meeting

18. Demers D M, Bass J W, Vincent J M, Person D A, Noyes D K, Staege C M, Samlaska C P, Lockwood N H, Regnery R L, Anderson B E 1995 Cat-scratch disease in Hawaii: etiology and seroepidemiology. Journal of Pediatrics 127: $23-26$

19. Frean J, Arndt S, Spencer D 2002 High rate of Bartonella henselae infection in HIV-positive outpatients in Johannesburg, South Africa. Transactions of the Royal Society for Tropical Medicine and Hygiene 96: 549-550

20. Gillespie T N, Washabau R J, Goldschmidt M H, Cullen J M, Rogala A R, Breitschwerdt E B 2003 Detection of Bartonella henselae and Bartonella clarridgeiae DNA in hepatic specimens from two dogs with hepatic disease. Journal of the American Veterinary Medical Association 222: 47-51

21. Harrus S, Waner T, Aizenberg I, Foley J E, Poland A M, Bark H 1998 Amplification of ehrlichial DNA from dogs 34 months after infection with Ehrlichia canis. Journal of Clinical Microbiology 36: 73-76

22. Houpikian P, Raoult D 2003 Western immunoblotting for Bartonella endocarditis. Clinical Diagnostic Laboratory Immunology 10: 95-102

23. Jacomo V, Kelly P J, Raoult D 2002 Natural history of Bartonella infections (an exception to Koch's postulate). Clinical and Diagnostic Laboratory Immunology 9: 8-18

24. Jameson P, Greene C, Regnery R, Dryden M, Marks A, Brown J, Cooper J, Glaus B, Greene R 1995 Prevalence of Bartonella henselae antibodies in pet cats throughout regions of North America. Journal of Infectious Diseases 172: 1145-1149

25. Kawahara M, Ito T, Suto C, Shibata S, Rikihisa Y, Hata K, Hirai K 1999 Comparison of Ehrlichia muris strains isolated from wild mice and ticks and serologic survey of humans and animals with E. muris as antigen. Journal of Clinical Microbiology 37: 1123-1129

26. Kelly P J, Matthewman L A, Mahan S M, Semu S, Peter T, Mason P R, Brouqui P, Raoult D 1994 Serological evidence for antigenic relationships between Ehrlichia canis and Cowdria ruminantium. Research in Veterinary Science 56: 170-174

27. Kelly P J, Matthewman L A, Hayter D, Downey S, Wray K, Bryson N R, Raoult D 1996 Bartonella (Rochalimaea) henselae in southern Africa - evidence for infections in domestic cats and implications for veterinarians. Journal of the South African Veterinary Association 67: 182-187

28. Kelly P J, Rooney J J, Marston E L, Jones D C, Regnery R L 1998 Bartonella henselae isolated from cats in Zimbabwe. Lancet 351: 1706

29. Kelly P J 2000 Canine ehrlichioses: an update. Journal of the South African Veterinary Association 71: 77-86

30. Kelly P J, Meads N, Theobald A, Fournier P-E, Raoult D 2004 Rickettsia felis, Bartonella henselae, and B. clarridgeiae, New Zealand. Emerging Infectious Diseases 10: 967-968

31. Kitchell B E, Fan T M, Kordick D, Breitschwerdt E B, Wollenberg G, Lichtensteiger C A 2000 Peliosis hepatis in a dog infected with Bartonella henselae. Journal of the American Veterinary Medical Association 216: 519_ 523

32. Kordick D L, Brown T T, Shin K, Breitschwerdt E B 1999 Clinical and pathologic evaluation of chronic Bartonella henselae or Bartonella clarridgeiae infection in cats. Journal of Clinical Microbiology 37: 1536-1547

33. Kordick S K, Breitschwerdt E B, Hegarty B C, Southwick K L, Colitz C M, Hancock S I, Bradley J M, Rumbough R, McPherson J T, MacCormack J N 1999 Coinfection with multiple tick-borne pathogens in a Walker Hound kennel in North Carolina. Journal of Clinical Microbiology 37: 2631-2638

34. La Scola B, Davoust B, Boni M, Raoult D 2002 Lack of correlation between Bartonella DNA detection within fleas, serological results, and results of blood culture in a Bartonella-infected stray cat population. Clinical Microbiology and Infection 8:345-351

35. Liang Z, Raoult D 2000 Differentiation of Bartonella species by a microimmunofluorescence assay, sodium dodecyl sulfate-polyacrylamide gel electrophoresis, and Western immunoblotting. Clinical Diagnostic Laboratory Immunology 7: 617-624

36. Matthewman L A, Kelly P J, Bobade P A Tagwira M, Mason P R, Majok A, Brouqui P, Raoult D 1993 Infections with Babesia canis and Ehrlichia canis in dogs in Zimbabwe. Veterinary Record 133: 344-346

37. Matthewman L A, Kelly P J, Mahan S M Semu D, Tagwira M, Bobade P A, Brouqui P, Mason P R, Raoult D 1993 Western blot and indirect fluorescent antibody testing for antibodies reactive with Ehrlichia canis in sera from apparently healthy dogs in Zimbabwe. Journal of the South African Veterinary Association 64: 111-115

38. Matthewman L A, Kelly P J, Mahan S M, Semu S M, Mason P R, Bruce D, Brouqui P, Raoult D 1994 Reactivity of sera collected from dogs in Mutare, Zimbabwe, to antigens of Ehrlichia canis and Cowdria ruminantium. Veterinary Record 134: 498-499

39. Mexas A M, Hancock S I, Breitschwerdt E B 2002 Bartonella henselae and Bartonella elizabethae as potential canine pathogens. Journal of Clinical Microbiology 40: 4670-4674

40. Michau T M, Breitschwerdt E B, Gilger B C, Davidson M G 2003 Bartonella vinsonii subspecies berkhoffi as a possible cause of anterior uveitis and choroiditis in a dog. Veterinary Ophthalmology 6: 299-304

41. Pappalardo B L, Brown T, Gookin J L, Morrill C L, Breitschwerdt E B 2000 Granulomatous disease associated with Bartonella infection in 2 dogs. Journal of Veterinary Internal Medicine 14: 37-42

42. Parola P, Inokuma H, Camicas J L, Brouqui $\mathrm{P}$, Raoult D 2001 Detection and identification of spotted fever group Rickettsiae and Ehrlichiae in African ticks. Emerging Infectious Diseases 7: 1014-1017

43. Pretorius A M, Kelly P J 1998 Serological survey for antibodies reactive with Ehrlichia canis and E. chaffeensis in dogs from the Bloemfontein area, South Africa. Journal of the South African Veterinary Association 69: 126-128

44. Pretorius A M, Kelly P J, Birtles R J, Raoult D 1999 Isolation of Bartonella henselae from a serologically negative cat in Bloemfontein, South Africa. Journal of the South African Veterinary Association 70: 154-155

45. Pretorius A M, Venter T P, van der Ryst E, Kelly P J 1999 Possible human ehrlichiosis in the Free State. South African Medical Journal 89: 961

46. Raoult D, Ndihokubwayo J B, TissotDupont H, Roux V, Faugere B, Abegbinni R, Birtles R J 1998 Outbreak of epidemic typhus associated with trench fever in Burundi. Lancet 352: 353-358

47. Rikihisa Y, Ewing S A, Fox J C 1994 Western immunoblot analysis of Ehrlichia chaffeensis, E. canis, or E. ewingii infections in dogs and humans. Journal of Clinical Microbiology 32: 2107-2112

48. Rolain J M, Franc M, Davoust B, Raoult D 
2003 Molecular detection of Bartonella quintana, B. koehlerae, B. henselae, B. clarridgeiae, Rickettsia felis, and Wolbachia pipientis in cat fleas, France. Emerging Infectious Diseases 9: 338-342

49. Rust M K, Dryden M W 1997 The biology, ecology, and management of the cat flea. Annual Reviews in Entomology 42: 451-473

50. Sander A, Zagrosek A, Bredt W, Schiltz E,
Piemont Y, Lanz C, Dehio C 2000 Characterization of Bartonella clarridgeiae flagellin (FlaA) and detection of antiflagellin antibodies in patients with lymphadenopathy. Journal of Clinical Microbiology 38: 2943-2948

51. Savadye D T, Kelly P J, Mahan S M 1998 Evidence to show that an agent that crossreacts serologically with Cowdria ruminantium in Zimbabwe is transmitted by ticks.
Experimental and Applied Acarology 22: 111-122

52. Tsukahara $\mathrm{M}$, Tsuneoka $\mathrm{H}$, Iino $\mathrm{H}$, Ohno $\mathrm{K}$, Murano I 1998 Bartonella henselae infection from a dog. Lancet 352: 1682

53. van Heerden J 1982 A retrospective study on 120 natural cases of canine ehrlichiosis. Journal of the South African Veterinary Association 53: 17-22 